Received: 12 August 2019

Revision received: 9 October 2019

Copyright $\odot 2019$ ESTP

Accepted: 14 October 2019

www.estp.com.tr

DOI 10.12738/estp.2019.4.005 • October $2019 \cdot 19(4) \cdot 65-79$

Article

\title{
How to Survive in Academia: Demands, Resources and Study Satisfaction Among Polish PhD Students
}

\author{
Konrad Kulikowski \\ Jagiellonian University, Krakow, Poland \\ Emil Antipow \\ Jagiellonian University, Krakow, Poland
}

\author{
Anna Potoczek \\ Jagiellonian University, Krakow, Poland \\ Szymon Król \\ Jagiellonian University, Krakow, Poland
}

\begin{abstract}
There is a great deal of research showing that $\mathrm{PhD}$ students suffer from dissatisfaction. Whereas most studies in this field strived to identify factors negatively related to $\mathrm{PhD}$ students' well-being, still little is known about factors positively related to the well-being of young academics. We based our analysis on the Job Demands-Resource Theory (JD-R), to identify study resources positively related to PhD student satisfaction. Building on the results of the survey conducted among $360 \mathrm{PhD}$ students of the Jagiellonian University (Poland) we singled out seven main resources most strongly related to $\mathrm{PhD}$ student satisfaction. Our findings might provide initial evidence about what type of resources are worth developing to maximize $\mathrm{PhD}$ student well-being. These results could be of particular importance and interest for candidates who look for $\mathrm{PhD}$ positions and $\mathrm{PhD}$ students already working in different academic environments, as well as for broader academic community and higher education policymakers.
\end{abstract}

\section{Keywords}

PhD students $\bullet$ job satisfaction $\bullet$ job demands $\bullet$ job resources $\bullet$ doctoral students well-being

Correspondence to Konrad Kulikowski, PhD, Institute of Psychology, Jagiellonian University. Ingardena 6, 30-060, Kraków, Poland. Email: konrad.kulikowski@doctoral.uj.edu.pl

Citation: Kulikowski, K., Potoczek, A., Antipow, E., \& Król, S. (2019). Demands, resources and study satisfaction among Polish PhD Students. Educational Sciences: Theory and Practice, 19(4), 65 - 79. http://dx.doi.org/10.12738/estp.2019.4.005 


\section{PhD Students Stress}

There is a growing body of research showing an alarming rate of dissatisfaction and stress among PhD students. Recently, Evans, Bira, Gastelum, Weiss, and Vanderford (2018) have warned about the mental health crisis among graduate students. In a research study, among 2,279 individuals $(90 \% \mathrm{PhD}$ students) from 26 countries representing diverse fields of research, $41 \%$ of students were found to suffer from anxiety and 39\% from depression. Moreover, graduate students were six times more likely to experience depression and anxiety compared to the general population. Similarly, Levecque, Anseel, De Beuckelaer, Van der Heyden, and Gisle (2017) based on the investigation of a sample of more than 3,600 Belgian $\mathrm{PhD}$ students alarmed that one in two $\mathrm{PhD}$ students experiences psychological distress and that prevalence of mental health problems is almost 2.5 times higher in $\mathrm{PhD}$ students than in general highly educated population. In a similar vein, Garcia-Williams, Moffitt, and Kaslow (2014, p. 554) have found among 301 graduate students that "more than half endorsed feeling nervous, irritable, stressed, anxious, lonely, or having fights/arguments", what is even worse, more than 7\% reported having suicidal thoughts.

A study by Stubb, Pyhältö, and Lonka (2011) showed that, among 669 doctoral students from the University of Helsinki, 56\% reported the academic community as a source of burden. Reviewing papers related to PhD students' well-being, Tsai and Muindi (2016) reported seven studies that have shown that generally more than 40 percent of surveyed $\mathrm{PhD}$ students declared having some emotional or stress-related problems (for details see Tsai \& Muindi, 2016). Also, leading scientific journals such as Nature or Science systematically warn about severe problems with PhD students' well-being (see Bernstein, 2015).

Although there is a great deal of empirical evidence showing that $\mathrm{PhD}$ students suffer from immense dissatisfaction, still little is known about factors related to the well-being of young academics. Research studies on factors related to $\mathrm{PhD}$ student dissatisfaction mention mixed factors such as work-life balance, support and mentoring from the supervisor (Devine \& Hunter, 2017; Evans et al., 2018; Juniper, Walsh, Richardson, \& Morley, 2012), work-family conflict, job demands, job control and leadership style of the supervisor (Levecque et al., 2017), supervisor support (Devine \& Hunter, 2017), opportunity for development, facilities, home and health experiences, research progress, social support, university policy toward PhD and more (Juniper et al., 2012).

Thus, generally it seems that it is rather clear that there is a problem of unfavorably experienced socio-psychological well-being among PhD students, but it is not clear, however, what the causes or even correlates of this problem are. Therefore, it seems vital to continue the search for factors related to $\mathrm{PhD}$ students' well-being. With the following study, we continue this line of research by asking what factors are related to $\mathrm{PhD}$ student satisfaction at Jagiellonian University - one of the most prominent Polish universities. However, our study differs from other studies related to PhD students' well-being and expands on their findings for at least two reasons.

First, we based our analysis of the correlates of the PhD students' satisfaction on the Job DemandsResource Theory (JD-R) (Bakker \& Demerouti, 2017) as a well-established theory of human well-being in a workplace, whereas most of the other studies usually analyzed $\mathrm{PhD}$ students' well-being without referring to any theoretical framework, which limited possible interpretations and predictions. JD-R proposed two broad characteristics of the work environment related to well-being (Bakker \& Demerouti, 2017) - one classified as resources, and second, as demands. Although JD-R theory was developed in the context of work environment, its assumptions were also successfully applied in the context of learning environment (see Bakker, Sanz-Vergel, \& Kuntze, 2014; Salanova, Schaufeli, Martinez, \& Breso, 2010; Salmela-Aro \& Upadyaya, 2014). 
In the scope of JD-R, (study) demands might be defined as all aspects of study environment requiring sustained effort, and thus, generating certain psychophysiological costs, causing difficulties, and hindering the process of achieving important study goals. In contrast, (study) resources are all study characteristics functioning in achieving goals connected to studying, reducing the costs related to the demands and stimulating PhD students' growth and development (for details see Bakker \& Demerouti, 2017). Consequently, we based this study on a well-established theoretical framework, which allowed us to interpret aspects of study environment as job demands or resources environment (see Bakker et al., 2014; Salanova et al., 2010; Salmela-Aro \& Upadyaya, 2014). Our main idea is that identification of resources most strongly related to $\mathrm{PhD}$ students' satisfaction might shed light on what resources students can build to promote their well-being.

Second, most studies investigating $\mathrm{PhD}$ students' well-being strived to identify factors negatively related to PhD students' well-being (i.e., study demands). What we do in the following research is to identify not only demands, but also positive aspects of $\mathrm{PhD}$ studies (i.e., identify and emphasize study resources). Consequently, by highlighting the most powerful study resources, we would like to encourage PhD students to bottom-up craft their study environment into a more resourceful place by mobilizing the resources with the highest potential to increase their well-being.

Our line of reasoning is based on research in the scope of the JD-R theory suggesting that, for improvement of well-being, it is crucial to encourage employees to increase the level of resources, as reducing job demands might be unrelated or might even have a negative influence on well-being. There is empirical evidence that interventions based on JD-R theory that address resource building are successful in improving work-related well-being (e.g., Knight, Patterson, \& Dawson, 2017; Van Wingerden, Bakker, \& Derks, 2016), whereas self-reducing of job demands by employees is not an effective way of improving the well-being (Petrou, Demerouti, Peeters, Schaufeli, \& Hetland, 2012; Tims, Bakker, \& Derks, 2012; 2013).

This study also tries to reach more senior academics by providing them with information on the most crucial job resources related to $\mathrm{PhD}$ students' well-being. This might be of particular importance as Van Wingerden, Derks, and Bakker (2018) have shown that in intern - supervisor relationship, providing interns with job resources contributes to their performance. The knowledge about study resources might also help the academic community to create policies, contributing to building a fit between a doctoral student and their study environment (Baker \& Pifer, 2015; Ward \& Brennan, 2018). We believe that knowledge about the most important study resources of $\mathrm{PhD}$ students could be helpful for senior academics who work as $\mathrm{PhD}$ supervisors in terms of building the relationship between supervisor and $\mathrm{PhD}$ students based on trust and satisfaction.

In conclusion, the key factor in improving $\mathrm{PhD}$ candidates' satisfaction might not only be to understand what the most important negative factors that influence their well-being are, but also what the potential job resources for $\mathrm{PhD}$ students are. Therefore, we put forward two research questions addressing the demands and resources of PhD students:

Q1: What $\mathrm{PhD}$ study resources are most strongly positively related to $\mathrm{PhD}$ candidates' satisfaction? $\mathrm{Q} 2$ : What $\mathrm{PhD}$ study demands are most strongly negatively related to $\mathrm{PhD}$ candidates' satisfaction?

\section{Method}

\section{Participants}

The invitation to the study was sent to all (about 3500) Jagiellonian University PhD students via the official university mailbox. In time where this study was conducted, $\mathrm{PhD}$ students in Polish universities 
were not university employees, but were students and had no or only minor financial support in form of scholarships from university. In Poland, $\mathrm{PhD}$ studies according to law requirements generally last 4 years with a possibility of a maximum 2-year extension in the case of prolonged research.

In general, 446 participants (285 women) took part in this study $(M=27.85, S D=3.76$, ) yielding an approximatively $13 \%$ response rate. These were 86 (51 women) students of first year $\left(M_{\text {age }}=26.31, S D=\right.$ $3.46)$ and 360 students (234 women) of higher years $\left(M_{\mathrm{age}}=28.21, S D=3.74\right)$. In this analysis, we use only responses from students from second and higher years, as only these $\mathrm{PhD}$ students had the chance to experience demands and resources for at least one academic year. Students of the first year while taking part in the survey were participating in the $\mathrm{PhD}$ program only for 3 months and thus, they were excluded from the main analyses.

\section{Instruments}

PhD students' well-being as satisfaction with doctoral studies. In this study we measured one aspect of subjective well-being i.e., PhD students' satisfaction with doctoral studies, which refers to a person's cognitive evaluation of his or her PhD study. We are aware that well-being is a broad category and in this study, we refer only to one particular domain of well-being (see Diener, Suh, Lucas, \& Smith, 1999), however this well-being component i.e., overall satisfaction with doctoral studies might be of crucial importance for live satisfaction of $\mathrm{PhD}$ students.

$\mathrm{PhD}$ student's well-being as satisfaction with doctoral studies was measured using item based on Cantril Self-Anchoring Striving Scale (Cantril, 1965). This is a commonly used measure in subjective wellbeing assessment measuring life evaluation (see Gallup, 2018). Specifically, participants were presented with the vertical scale from 10 - best doctoral studies I could imagine to 0 - worst doctoral studies I could imagine and the following instruction: "Please look at the scale below. The bottom of the scale, marked as 0 , represents the worst doctoral studies you could imagine, while the top of the scale, marked as 10 , represents best doctoral studies you could imagine. On which point of this scale you see your own doctoral studies?" Although there are some popular misconceptions about single-item measures, single item satisfaction measures are proved to be psychometrically valid and provide useful information (Cheung \& Lucas, 2015; Wanous \& Hudy, 2001). In addition, the satisfaction with doctoral studies is a unidimensional construct, clear and vital to our respondents and narrowed to one particular domain - which further justifies use of single-item measure (see Wanous, Reichers, \& Hudy, 1997).

Demands and resources scale. Participants were presented with two separate lists (i.e., a list of advantages and a list of disadvantages of doctoral studies) and this measurement method was inspired by Salanova et al. (2010). The first list contained 26 possible demands ( 26 items) connected to doctoral studies, and the second one - a list of 23 potential resources ( 23 items). The complete lists of resources and demands used in this study can be found in Tables 1 and 2, respectively. The instruction for study resources was: "From the list below, please select the factors that, in your opinion, in the last academic year, have helped you in studying or facilitated your success in the doctoral studies at the Jagiellonian University". Instructions regarding demands were similar, however, here participants were asked to select "those factors which made their PhD studies difficult or which prevented them from succeeding in doctoral studies".

Each participant was presented with a list of 26 demands and then with a list of 23 resources and their task was to select (by clicking in a checkbox) those demands and resources that they have experienced during the past year of their PhD studies. When participants selected a given item on resources or demands list, the response was coded as Yes (or 1 in a numeric form) - participant experiences this item, when he or she did 
not select the item response was coded as $N o$ (or 0 ) - participant does not experience this item. Thus, in sum, this survey consisted of 26 demands and 23 resources with a dichotomous (yes/no) response options.

The procedure of demands and resources lists creation. To best represent potential study demands and resources of Jagiellonian University $\mathrm{PhD}$ students, these lists were developed in several steps. First, all Jagiellonian University $\mathrm{PhD}$ students were sent an e-mail with an invitation to participate in a study focused on PhD students' opinions. After team formation, team members (four Jagiellonian University $\mathrm{PhD}$ students who respond to e-mail invitation, including two authors of this paper) constructed and discussed a list of potential 58 demands and 57 resources of $\mathrm{PhD}$ studies. Next, each item describing resources and demands was assessed according to their relevance anonymously by 9 competent judges not engaged in the construction of the initial list of demands and resources. Raters were councillors of the PhD Students' Society. These raters were chosen as the $\mathrm{PhD}$ students' society is an official (according to the Polish law) representation of doctoral students in University authorities. For example, councillors of the PhD Students' Society are obligated to give opinions and accept all newly opened $\mathrm{PhD}$ programs, they also accept or rejects proposals for the position of the head of a given doctoral program, and therefore we assume that councillors of the PhD Students' Society are best acquainted with the most important demands and resources of Jagiellonian University $\mathrm{PhD}$ students. Finally, councillors' ratings were discussed and critically evaluated among team members and yield the final lists of $26 \mathrm{PhD}$ studies demands and 23 resources. All included resources were rated as resource by at least 7 counsellor and all demands were rated as demand by at least 4 councillors, except one "Inappropriate work of the university's administrative staff", which was added as additional question as a result of discussion of team members. The difference in rating agreements for demand and resource items stems from different distribution of ratings for resources and demands among raters. This final list of study resources and demands (see Table 1 and 2) was previously used in a study by Kulikowski and Damaziak (2017).

Other questions. Participants were asked 3 additional questions regarding their activities in the previous academic year, such as: "Did you receive a doctoral scholarship?", "Did you work outside of the academia doing a job not related to your academic work?", "Did you conduct classes for students?" The yes answer was coded as 1 , the no answer, as 0 .

\section{Procedure}

The study was anonymous and conducted online. Invitation to take part in the study was sent mainly via mailing lists for Jagiellonian University $\mathrm{PhD}$ students. Participants were asked about study satisfaction, demands and resources, and about some additional demographic information such as age, sex, affiliation, and year of studies. Participants were also asked if, in the previous academic year, they received a doctoral scholarship, did professional work outside of the academia, and conducted classes with master or bachelor students (this variable was finally not included in the analysis due to a technical error). This study was fully anonymized, conducted on the adult population, does not consist of the physically or mentally exhausting items, does not refer to controversial, threatening or private issues, neither involves any kind of active intervention in human behavior. Participants have been highly educated adults with full autonomy to take part in this study or refuse. Moreover, participants could stop filling a survey at any time.

\section{Data analysis}

In the first step of the analysis, we calculated a frequency of occurrence of each demand and resource by creating 0/1 dichotomous variable - coding responses yes for each demand/resource questions as 1 and then summing them up. Then, for each of the study demands and resources, we calculated pointbiserial correlation with study satisfaction. In the next step of the analysis, we introduced demands and 
resources significantly related to study satisfaction into a regression model predicting study satisfaction. Because subsequent demands and resources are introduced into a regression model as a dichotomous variable $(1=$ yes; $0=n o)$, we could observe changes in satisfaction level among students experiencing each of the resources/demands in comparison to students not experiencing them (assuming other demands/resources in a model to be on the same level). Additionally, in each regression model, we controlled for sex $(1=$ female; $0=$ male), age, field of study (coded as numbers from 1 to 10 where each number represents separated study field e.g., $1=$ biological science), doing professional work outside the academia $(1=$ yes; $0=n o)$, receiving scholarship $(1=$ yes; $0=n o)$. This strategy of analyses allowed us to capture general resources and demands most strongly related to $\mathrm{PhD}$ students' satisfaction when controlling for other demands/resources in the model and possibly confounding variables such as sex, age, field of study, doing professional work outside the academia, receiving scholarship.

\section{Results}

\section{Descriptive Analysis}

The frequency of reporting each job demands among participants and correlations between study resources/demands and $\mathrm{PhD}$ students' satisfaction are presented in Table 1 and Table 2.

Table 1. Frequency of experiencing each of the study resources among surveyed PhD students and their correlations with PhD students'satisfaction.

\begin{tabular}{|c|c|c|}
\hline & $\begin{array}{c}\text { Correlation } \\
\text { with satisfaction }\end{array}$ & $\begin{array}{c}\text { \% of response } \\
\text { Yes }\end{array}$ \\
\hline Support and kindness received from academic workers. & $.44 * *$ & 34 \\
\hline Collaboration with experts in the field of the PhD topic. & $.33 * *$ & 19 \\
\hline Clear expectations from supervisor towards the $\mathrm{PhD}$ student. & $.29 * *$ & 30 \\
\hline Support from the supervisor in preparing a doctoral dissertation. & $.28 * *$ & 41 \\
\hline Supervisor who is an authority in the scientific environment. & $.28 * *$ & 41 \\
\hline Participation in classes for small groups of students. & $.26 * *$ & 14 \\
\hline Clear information about what one should do to complete a $\mathrm{PhD}$ program. & $.26 * *$ & 17 \\
\hline Prestige of studies at this university. & $.21 * *$ & 35 \\
\hline $\begin{array}{l}\text { Support received from administration staff in solving problems related to the } \\
\text { PhD program. }\end{array}$ & $.20 * *$ & 34 \\
\hline Possibility of conducting own interesting research. & $.19 * *$ & 33 \\
\hline Free access to scientific journals. & $.17 * *$ & 42 \\
\hline Access to software necessary for scientific work. & $.17 * *$ & 31 \\
\hline Becoming friends with other PhD students. & $.16^{* *}$ & 30 \\
\hline Participation in classes that help to develop professional competences. & $.16^{* *}$ & 11 \\
\hline Working and studying in the buildings that are next to each other. & $.15^{* *}$ & 27 \\
\hline Support received from other $\mathrm{PhD}$ students. & .10 & 33 \\
\hline $\begin{array}{l}\text { Participation in events for the PhD students' community, e.g. trips and } \\
\text { integration parties. }\end{array}$ & .09 & 09 \\
\hline $\begin{array}{l}\text { Caring for PhD students interests by } \mathrm{PhD} \text { students' representatives [on the } \\
\text { Council of the Institute / Faculty]. }\end{array}$ & .06 & 09 \\
\hline Discounts for public transport. & .05 & 75 \\
\hline Health insurance paid by the university. & .02 & 39 \\
\hline Possibility of prolonging the $\mathrm{PhD}$ program. & -.03 & 24 \\
\hline Financing of scientific activities of the PhD students [by the Doctoral Society]. & -.05 & 28 \\
\hline Participation in foreign exchanges. & -.06 & 15 \\
\hline
\end{tabular}


Table 2. Frequency of experienced study demands among surveyed PhD students and their correlations with PhD students' satisfaction

\begin{tabular}{|c|c|c|}
\hline & $\begin{array}{c}\text { Correlation } \\
\text { with satisfaction }\end{array}$ & $\begin{array}{c}\text { \% response } \\
\text { Yes }\end{array}$ \\
\hline Lack of academic workers' respect for PhD students. & $-.35^{* *}$ & 25 \\
\hline $\begin{array}{l}\text { Lack of ambition among the academic workers to compete with the best uni- } \\
\text { versities in the world. }\end{array}$ & $-.34^{* *}$ & 36 \\
\hline Obligatory participation in classes that teach nothing but are time-consuming. & $-.31^{* *}$ & 79 \\
\hline Treating PhD students as a 'cheap labor force'. & $-.30^{* *}$ & 58 \\
\hline Lack of support from the supervisor in preparing a dissertation. & $-.29^{* *}$ & 22 \\
\hline $\begin{array}{l}\text { Being overloaded with tasks related to participation in classes for the } \mathrm{PhD} \text { stu- } \\
\text { dents. }\end{array}$ & $-.28^{* *}$ & 44 \\
\hline Lack of supervisor's time for a PhD student. & $-.28^{* *}$ & 23 \\
\hline Unclear rules of receiving scholarships. & $-.27^{* *}$ & 39 \\
\hline Lack of contact with world-famous scientists. & $-.25^{* *}$ & 39 \\
\hline $\begin{array}{l}\text { Not taking into account PhD students' opinions when making decisions by } \\
\text { faculty / institute authorities. }\end{array}$ & $-.25^{* *}$ & 29 \\
\hline Not being paid for teaching students. & $-.23^{* *}$ & 61 \\
\hline Little possibilities of financing own research. & $-.22^{* *}$ & 48 \\
\hline Lack of classes conducted by experts. & $-.22^{* *}$ & 43 \\
\hline Lack of courses and classes developing the skills needed in scientific work. & $-.21^{* *}$ & 50 \\
\hline Lack of financing of scientific publications. & $-.20^{* *}$ & 40 \\
\hline Lack studying space for the PhD students. & $-.20^{* *}$ & 27 \\
\hline Lack of the possibility to work and study on PhD studies at the same time. & $-.16^{* *}$ & 49 \\
\hline Too many PhD students under the supervision of one supervisor. & $-.16^{* *}$ & 16 \\
\hline Inappropriate work of the university's administrative staff. & $-.15^{* *}$ & 14 \\
\hline High level of competition between the PhD candidates. & $-.15^{* *}$ & 41 \\
\hline Being too overloaded with work by the supervisor & $-.14^{* *}$ & 16 \\
\hline No access to a good Wi-Fi connection. & $-.14^{* *}$ & 29 \\
\hline Lack of information about possible career paths after the $\mathrm{PhD}$ studies. & $-.14^{* *}$ & 62 \\
\hline Classes schedule - classes taking place very early or very late during the day. & $-.12^{*}$ & 14 \\
\hline Inconvenient location of buildings in which classes take place. & $-.12^{*}$ & 13 \\
\hline Lack of information about grants and scholarships for the $\mathrm{PhD}$ students. & $-.11^{*}$ & 31 \\
\hline
\end{tabular}

Note. $* p<.05, * * p<.01$

\section{Demands, Resources and Phd Students' Satisfaction}

To identify demands and resources most strongly related to the $\mathrm{PhD}$ students' satisfaction level, we have created a multiple regression model with all demands and resources significantly related to the student satisfaction as predictors of PhD students' satisfaction and control variables. Due to missing variables in controls ( 2 missing in "year of study", 1 in "scholarship" and 1 in "work outside academia"), we included 356 cases in the final model. In this regression model we included only resources and demands significantly correlated with study satisfaction i.e., all 26 demands and 15 resources (see Table 1 and Table 2). Results of the regression analysis are presented in Table 3. The created multiple regression model fit the data reasonably well $\left(F_{(47,308)}=8.63, p<.001\right)$ and explains about $57 \%$ of the variance in PhD students' satisfaction $\left(R^{2}=.57\right)$. As can be seen in Table 3 , there were seven resources and seven demands significantly related to the $\mathrm{PhD}$ students' satisfaction with a value of $p<.05$. 
Table 3. Study demands and resources as predictors of PhD students' satisfaction level - full regression model

\begin{tabular}{|c|c|c|c|c|}
\hline & $b$ & $S E$ & $\beta$ & $p$ \\
\hline \multicolumn{5}{|l|}{ Study demands } \\
\hline Lack of support from the supervisor in preparing a dissertation. & -.72 & .26 & -.14 & .006 \\
\hline Obligatory participation in classes that teach nothing but are time-consuming. & -.65 & .23 & -.13 & .005 \\
\hline $\begin{array}{l}\text { Lack of ambition among the academic workers to compete with the best universities in } \\
\text { the world. }\end{array}$ & -.56 & .20 & -.13 & .006 \\
\hline Lack of academic workers' respect for PhD students. & -.49 & .22 & -.10 & .024 \\
\hline Being overloaded with tasks related to participation in classes for the PhD students. & -.46 & .19 & -.11 & .018 \\
\hline Lack of courses and classes developing the skills needed in scientific work. & -.38 & 18 & -.09 & .034 \\
\hline Little possibilities of financing own research. & -.38 & .19 & -.09 & .044 \\
\hline Treating PhD students as a "cheap labor force". & -.34 & .19 & -.08 & .071 \\
\hline Inconvenient location of buildings in which classes take place. & -.29 & .26 & -.05 & .264 \\
\hline Inappropriate work of the university's administrative staff. & -.25 & .26 & -.04 & .328 \\
\hline Unclear rules of receiving scholarships. & -.21 & .18 & -.05 & .251 \\
\hline Lack of information about grants and scholarships for the $\mathrm{PhD}$ students. & -.17 & .19 & -.04 & .376 \\
\hline Lack of contact with world-famous scientists. & -.13 & .22 & -.03 & .560 \\
\hline No access to a good Wi-Fi connection. & -.10 & .20 & -.02 & .597 \\
\hline Classes schedule - classes taking place very early or very late during the day. & -.10 & .25 & -.02 & 693 \\
\hline Lack studying space for the PhD students. & -.09 & .21 & -.02 & 648 \\
\hline High level of competition between the $\mathrm{PhD}$ candidates. & -.07 & .19 & -.02 & .713 \\
\hline Lack of financing of scientific publications. & -.05 & .19 & -.01 & 796 \\
\hline Being too overloaded with work by the supervisor & -.05 & .23 & -.01 & .832 \\
\hline Too many PhD students under the supervision of one supervisor. & -.03 & .24 & .00 & .914 \\
\hline Lack of supervisor's time for a PhD student. & -.02 & .25 & .00 & .927 \\
\hline Lack of classes conducted by experts. & .01 & .21 & .00 & .972 \\
\hline Not being paid for teaching students. & .01 & .20 & .00 & .952 \\
\hline Lack of the possibility to work and study on PhD studies at the same time. & .06 & .19 & .02 & .735 \\
\hline $\begin{array}{l}\text { Not taking into account PhD students' opinions when making decisions by faculty / } \\
\text { institute authorities. }\end{array}$ & .08 & .21 & .02 & .700 \\
\hline $\begin{array}{l}\text { Lack of information about possible career paths after the } \mathrm{PhD} \text { studies. } \\
\qquad \text { Study resources }\end{array}$ & .11 & .19 & .03 & .536 \\
\hline Support and kindness received from academic workers. & .72 & .20 & .16 & .000 \\
\hline Collaboration with experts in the field of the $\mathrm{PhD}$ topic. & .57 & .24 & .11 & .017 \\
\hline Participation in classes for small groups of students. & .57 & .26 & .09 & .033 \\
\hline Possibility of conducting own interesting research. & .54 & .19 & .12 & .005 \\
\hline Participation in classes that help to develop professional competences. & .53 & .27 & .08 & .049 \\
\hline Becoming friends with other PhD students. & .52 & .19 & .11 & .006 \\
\hline Access to software necessary for scientific work. & .44 & .20 & .10 & .025 \\
\hline Clear expectations from supervisor towards the $\mathrm{PhD}$ student. & .44 & .23 & .10 & .060 \\
\hline Prestige of studies at this university. & .36 & 19 & .08 & .061 \\
\hline Clear information about what one should do to complete a PhD program. & .24 & .24 & .04 & .323 \\
\hline $\begin{array}{l}\text { Support received from administration staff in solving problems related to the } \mathrm{PhD} \text { pro- } \\
\text { gram. }\end{array}$ & .21 & .19 & .05 & .277 \\
\hline Free access to scientific journals. & .08 & .18 & .02 & .650 \\
\hline Support from the supervisor in preparing a doctoral dissertation. & -.04 & .22 & -.01 & .864 \\
\hline Working and studying in the buildings that are next to each other. & -.15 & .20 & -.03 & .467 \\
\hline Supervisor who is an authority in the scientific environment. & -.17 & .20 & -.04 & .393 \\
\hline
\end{tabular}

Note. The model controls for age, study year, study field, sex, scholarship, work outside of the academia. Model included all demands and resources significantly correlated to study satisfaction as shown in Table 1 and Table $2 ; R^{2}=.57$. 
However, our regression model is quite complex as it includes 15 resources and 26 demands, yielding 41 predictors (many nonsignificant). Thus, in the next step of analysis, we have tested a simplified version of this model using only the predictors which $p$-values were below .05. The simplified multiple regression model consists of 7 demands and 7 resources that were significantly related to study satisfaction in the full model (see Table 4). This simplified model still fits the data reasonably well $\left(F_{(20,335)}=18.88, p\right.$ $<.001)$, and explains about $53 \%$ of the variance in $\mathrm{PhD}$ students' satisfaction $\left(R^{2}=.53\right)$. A comparison of the $R^{2}$ of full model (.57) with the $R^{2}$ of the simplified model, there is only $4 \%$ drop in predictive power of the model. This is a relatively small decrease after eliminating 27 predictors, thus simplified model might be reasonable and coherent version of demands and resources that act as essential predictors of $\mathrm{PhD}$ student's satisfaction.

Table 4. Study demands and resources as predictors of PhD students' satisfaction level - a simplified regression model

\begin{tabular}{|c|c|c|c|c|}
\hline & $b$ & $S E$ & $\beta$ & $p$ \\
\hline Study demands & & & & \\
\hline Obligatory participation in classes that teach nothing but are time-consuming. & -.79 & .22 & -.15 & .000 \\
\hline Being overloaded with tasks related to participation in classes for PhD students. & -.56 & .17 & -.13 & .001 \\
\hline Lack of academic workers' respect for PhD students. & -.64 & .19 & -.13 & .001 \\
\hline $\begin{array}{l}\text { Lack of ambition among the academic workers to compete with the best universities in the } \\
\text { world. }\end{array}$ & -.62 & .18 & -.14 & .001 \\
\hline Little possibilities of financing own research. & -.45 & .17 & -.11 & .007 \\
\hline Lack of courses and classes developing the skills needed in scientific work. & -.50 & .17 & -.12 & .003 \\
\hline $\begin{array}{c}\text { Lack of support from the supervisor in preparing a dissertation. } \\
\text { Study resources }\end{array}$ & -.95 & .20 & -.19 & .000 \\
\hline Support and kindness received from academic workers. & .79 & .19 & .18 & .000 \\
\hline Access to software necessary for scientific work. & .48 & .18 & .11 & .007 \\
\hline Participation in classes for small groups of students. & .63 & .25 & .10 & .012 \\
\hline Possibility of conducting own interesting research. & .48 & .18 & .11 & .008 \\
\hline Collaboration with experts in the field of the PhD topic. & .71 & .22 & .13 & .001 \\
\hline Becoming friends with other PhD students. & .60 & .18 & .13 & .001 \\
\hline Participation in classes that help to develop professional competences. & .69 & .26 & .11 & .008 \\
\hline
\end{tabular}

Note. The model controls for age, study year, study field, sex, scholarship, work outside of the academia. The simplified model included all demands and resources whose were significant predictors of study satisfaction in the full model presented in Table 3 . $R^{2}=.53$

\section{Discussion}

A considerable amount of literature has been published on the topic of $\mathrm{PhD}$ students' well-being (Evans et al., 2018; Levecque et al., 2017; Tsai \& Muindi, 2016). However, most of these studies were mainly focused on describing the level of well-being among young academics, but they have usually omitted factors positively related to PhD students' satisfaction. Therefore, the main aim of this study was to fill this gap in the literature and take a closer look at the factors associated with $\mathrm{PhD}$ students' satisfaction. To improve the robustness of our findings, we based the following research on the JD-R theoretical framework - one of the contemporary most widely used theory of human well-being in the workplace.

To identify study resources and demands most strongly related to the $\mathrm{PhD}$ students' well-being, we put forward two research question: "What $\mathrm{PhD}$ studies resources are most strongly positively related to $\mathrm{PhD}$ candidates' satisfaction?" and "What $\mathrm{PhD}$ studies demands are most strongly negatively related to $\mathrm{PhD}$ 
candidates' satisfaction?" Based on our findings, it might be stated that study resources most strongly positively related to the $\mathrm{PhD}$ candidates' satisfaction are support and kindness received from academic workers, collaboration with experts in the field of the $\mathrm{PhD}$ topic, participation in classes for small groups of students, possibility of conducting own interesting research, participation in classes that help to develop professional competences, becoming friends with other $\mathrm{PhD}$ students, and access to software necessary for scientific work. The study demands most strongly negatively related to satisfaction are the lack of support from the supervisor in preparing the dissertation, the obligatory participation in classes that teach nothing but are time-consuming, the lack of ambition among the academic workers to compete with the best universities in the world, the lack of academic workers' respect for $\mathrm{PhD}$ students, being overloaded with tasks related to participation in classes for $\mathrm{PhD}$ students, the lack of courses and classes developing the skills needed in scientific work, little possibilities of financing own research.

In this study, we wanted to adopt a positive approach and ask what makes $\mathrm{PhD}$ students satisfied rather than what makes them dissatisfied, thus in our discussion, we will concentrate mainly on study resources. The JD-R theory provides evidence that factors leading to the development of well-being are job resources and challenges, while job demands lead to ill-being. Importantly, the process of well-being and ill-being development constituted two separate processes (i.e., motivational process and health impairment processes). According to this line of reasoning, reduction of job demands might only lead to the reduction of ill-being (e.g., exhaustion, burnout, dissatisfaction), but cannot significantly increase well-being (e.g., satisfaction, engagement). Thus, by highlighting $\mathrm{PhD}$ candidates' studies resources most strongly related to satisfaction, our findings might contribute to a better understanding of $\mathrm{PhD}$ students' well-being and be of particular interests both for PhD candidates and the broad academic community.

Although our study is cross-sectional, we postulated that based on prior empirical findings and JD$\mathrm{R}$ theory propositions, it is reasonable to make causal assumption that study resources have a positive effect on study satisfaction. In fact, it is well-established by longitudinal, diary, and quasi-experimental studies that job resources influence employee well-being (Bakker \& Demerouti, 2017; Van Wingerden et al., 2016; Knight et al., 2017). Although the view that "there is no causation without a manipulation" is common (Bollen \& Pearl, 2013, p. 309), we assume that with a good knowledge of the theory and past research on the topic (Bollen \& Pearl, 2013), it might be reasonable to state a cause-effect relationships in observational studies (Pearl, 2010; Pearl \& Mackenzeie, 2018).

\section{How Findings Might Help Phd Students?}

Our findings might be of importance to PhD students for at least two reasons. First, by outlining the importance of study resources for the satisfaction, it might inform $\mathrm{PhD}$ candidates' decisions in their recruitment for doctoral studies. Secondly, the presented results might help to orient $\mathrm{PhD}$ candidates already working on their theses to build resources with high potential to increase their well-being.

Candidates looking for a $\mathrm{PhD}$ position in given labs/departments or other university units prior to applying for a position might consider analyzing the level of resources provided by these entities. Our research might be used to create a starting point and a useful heuristic tool in the form of a simple checklist addressing eight checkpoints, - resources most strongly related to PhD candidates' well-being. An example of this tool is presented in Figure 1.

The seven points depicted in Figure 1 create a heuristic way for assessment of potential resources in future PhD candidates' workplace. As any heuristics, this tool does not guarantee success, but it might provide a useful framework and motivate $\mathrm{PhD}$ candidates to establish a routine of analyzing study resources prior to choosing a specific $\mathrm{PhD}$ program. These points might also increase awareness among $\mathrm{PhD}$ 
candidates that, if one would like to foster one's well-being when doing academic work, it might be worth to consider not only the prestige of an academic unit or financial incentives, but also the possibility of receiving social support.

Will the work in this unit provide me with an opportunity to

1. Receive support and kindness from academic workers?

[yes/no]

2. Collaborate with experts in the field of the $\mathrm{PhD}$ topic?

[yes/no]

3. Participate in classes for small groups of students?

[yes/no]

4. Conduct my own interesting research?

[yes/no]

5. Participate in classes that help develop professional competences?

[yes/no]

6. Become friends with other $\mathrm{PhD}$ students?

[yes/no]

7. Access software necessary for scientific work?

[yes/no]

Figure 1. PhD candidate's heuristic checklist for analyzing the level of resources provided by an academic unit.

Moreover, in our view, the presented findings might be relevant not only for candidates who look for $\mathrm{PhD}$ positions, but also for $\mathrm{PhD}$ students already working in different academic environments. In this case, our findings might provide a general knowledge of what type of resources are worth developing to maximize their well-being.

The key factors in PhD students' satisfaction seem to be connected to one's working environment. Therefore, $\mathrm{PhD}$ candidates should consider working with academics who are experts in their fields, but - no less important - who can also be treated as a source of support. The importance of social support in $\mathrm{PhD}$ studies satisfaction is also visible in "Becoming friends with other PhD students" being among the most important factors influencing $\mathrm{PhD}$ students' satisfaction. This knowledge should encourage $\mathrm{PhD}$ candidates to engage in different social networks existing in their research unities. Although one might argue that the goal of academic work is to acquire new knowledge, not to make friends or have a good time with the coworkers, it is crucial to see that social resources are among the most powerful predictors of well-being. Not only our findings but also previous studies have shown that having a friend at work or spending time with people one likes is an important predictor of well-being (e.g., Kahneman, Krueger, Schkade, Schwarz, \& Stone, 2004).

Interestingly, against research findings, people are often unduly concentrated on aspects of work or life which in fact are not particularly relevant for well-being, a phenomenon called focusing illusion (Kahneman, Alan, Schkade, Schwarz, \& Stone, 2006). "When a judgment about an entire object or category is made with attention focused on a subset of that category, a focusing illusion is likely to occur, whereby the attended subset is overweighed relative to the unattended subset" (Schkade \& Kahneman, 1998, p.340). Therefore, our findings might encourage young scientists to develop not only professional competences and top publications portfolio, but also to actively build a supportive social network and friendships. Caring for supportive social relations might also be of particular importance in the case of $\mathrm{PhD}$ candidate-supervisor relationship. In this instance, $\mathrm{PhD}$ students might try to actively help supervisors to establish clear expectations toward them or together set measurable and precise goals (Payne, 2017; Taylor, 2018).

Other factors important for $\mathrm{PhD}$ students' satisfaction are connected to the quality of courses offered by the university. As our research has shown, participating in classes for small groups of students, which offer the development of specific professional skills, is a strong predictor of general satisfaction. Thus, $\mathrm{PhD}$ 
students should feel encouraged to choose courses with the abovementioned features. These findings stress the importance of thoughtful courses selection by $\mathrm{PhD}$ students with preference for those organized in small groups and allowing for learning skills and knowledge with direct application in $\mathrm{PhD}$ student's ongoing scientific work. It might be crucial for $\mathrm{PhD}$ candidates to avoid wasting their time on courses not related to their research topics or courses which are taken only to earn the required limit of course credit points.

Finally, other important factors responsible for $\mathrm{PhD}$ students' satisfaction refer to the research possibilities offered by the university. A chance to conduct research based on one's interests and having access to the software enabling this is also a crucial factor to feel satisfied with $\mathrm{PhD}$ studies. Our findings also emphasize the importance of conducting their own research projects by $\mathrm{PhD}$ students for their wellbeing. Although being a primary investigator in a scientific project might be intuitively seen as a demanding task, our results show that it is positively related to well-being, suggesting that it is perceived more as a challenge than a hindrance (see Crawford, Lepine, \& Rich, 2010). Thus, PhD students should look for means to conduct their own projects instead of being only a part of a big research project conducted by senior academics.

\section{Conclusions for the Academic Community and Policymakers}

Based on our findings, we can also draw some useful conclusions for the academic community and educational policymakers. Firstly, taking into account the importance of study resources for PhD student's well-being, academic community should seek actions aimed at increasing the levels of $\mathrm{PhD}$ students' resources as part of higher education policy. One of the means to increase study resources might be encouraging $\mathrm{PhD}$ candidates to be "active crafters" of their PhD study programs i.e., to actively look for different ways to build study resources along with study challenges. This idea refers to the concept of job crafting (see Wrzesniewski \& Dutton, 2001). This is "a specific form of proactive behavior in which the employee initiates change in the level of job demands and job resources in order to make his or her own job more meaningful, engaging, and satisfying" (Demerouti, 2014, p. 237). PhD students might initiate changes in their PhD studies organizations, interpersonal relations with other students and academic staff, to balance their job resources with job demands. Importantly, empirical studies provide evidence that job crafting is an effective way to increase the well-being (Harju, Hakanen, \& Schaufeli, 2016; Bakker, Tims, \& Derks, 2012; Sakuraya, Shimazu, Imamura, Namba, \& Kawakami, 2016; Tims, Bakker, \& Derks, 2015). Proactive job crafting taken to increase the well-being might be particularly relevant in the case of $\mathrm{PhD}$ candidates, as in this type of complex job, top-down activities planned and incorporated by university authorities might not sufficiently address needs of individual $\mathrm{PhD}$ student. If we agree that a particular set of resources is essential and worth to stimulate to maintain high well-being, there still might be different means to build the same resources depending on PhD studies context. Therefore, it might be a good strategy to encourage and "grant permission" for PhD students to actively craft their PhD jobs.

Secondly, our findings highlight the importance of $\mathrm{PhD}$ candidates perceived support from the academic community. It seems to be of high importance that senior academics realize how strong their support might influence PhD candidates' well-being. Particularly, our results draw special attention to the role of the supervisor in PhD students' well-being. It seems to be obvious for everyone in the academic community that the relationship with a supervisor is one of the most important aspects of $\mathrm{PhD}$ studies. However, as "nothing tends to evade our attention so persistently as that which is taken for granted" (Ichheiser, 1943, p. 204) still not sufficient attention is paid to competence, training, and evaluation of $\mathrm{PhD}$ supervisors. Obviously, competencies needed to supervise young scientists are not identical to the ones needed to succeed in academic work. Simply speaking, proficiency in publishing articles in the top journals 
and winning grant competitions is not the same as the ability to navigate $\mathrm{PhD}$ candidates through murky waters of his/her budding scientific career. Therefore, to build "supervisor support" resources, it might be important to start preparing senior academics for their role as supervisors in contrast to assuming that ability to supervise $\mathrm{PhD}$ students is an immanent attribute of every senior academic. The process of careful preparation and evaluation of supervisor performance might contribute to building productive and supportive working relationship between supervisor and student - a powerful study resource.

The concentration on study resources in this paper is also of some practical importance and might contribute to financial savings in the process of $\mathrm{PhD}$ students' well-being promotion. In most real-life situations, it might be difficult and costly to change demanding aspects of the PhD study programs even when they will be clearly identified. It is not readily achievable to increase 'ambition among the academic workers to compete with the best universities in the world', or immediately change financing policies at the universities. However, from our standpoint, there is always room for building job resources and crafting positive job behaviors. In other words, it might be easier, cheaper, and faster to build resources that reduce demands when it comes to modifications in $\mathrm{PhD}$ students' environment. For example, a single $\mathrm{PhD}$ candidate probably can find it challenging to change frustrating university bureaucracies but could relatively easily engage in supportive groups of other PhD candidates facing similar frustrations and trying to cope with them in a group. This line of reasoning stems from the JD-R theory proposition that job resources might buffer job demands (Bakker \& Demerouti, 2017), which means that even facing a high level of job demands one can still maintain high well-being as long as he or she has a high level of job resources.

This study has at least three main limitations. First, it is cross-sectional, thus our statements of casual relationships based on theory and previous research thus they are provisional valid (Pearl \& Mackenzeie, 2018) as long as we agree with the theoretical perspective that job resources predict well-being. Second, as $\mathrm{PhD}$ studies contexts might vary between countries and universities, the specific results might not be possible to be generalized over all $\mathrm{PhD}$ workplaces, thus they should be seen rather as heuristic suggestions than a precise road map. Third, although we try to minimize subjectivity and maximize representativeness of measured demands and resources, neither councillors nor team members involved in creation of demand and resources lists were chosen randomly from population of all $\mathrm{PhD}$ students, they were volunteers. Therefore, although unlikely, it is possible that some specific demands or resources were not captured in our demand and resource measure. That said we believe that our demands ( 26 items) and resources measures (23 items) capture sufficient number of general resources and demands to provide useful information.

\section{References}

Baker, V. L., \& Pifer, M. J. (2015). Antecedents and outcomes: theories of fit and the study of doctoral education. Studies in Higher Education, 40, 296 - 310. https://doi.org/10.1080/03075079.2013.823936

Bakker, A. B., \& Demerouti, E. (2017). Job Demands - Resources Theory: Taking Stock and Looking Forward. Journal of Occupational Health Psychology, 22, 273 - 285. https://doi.org/1.1037/ocp0000056

Bakker, A. B., Sanz-Vergel, A. I., \& Kuntze, J. (2014). Student engagement and performance: A weekly diary study on the role of openness. Motivation and Emotion, 39, 49 - 62. https://doi.org/1.1007/s11031-014-9422-5

Bernstein, R. (2015, May 13). Depression afflicts almost half of STEM graduate students at UC Berkeley Science [Post]. Retrieved from https:/www.sciencemag.org/careers/2015/05/depression-afflicts-almost-half-stemgraduate-students-uc-berkeley

Bollen, K. A., \& Pearl, J. (2013). Eight myths about causality and structural equation models. In S. L. Morgan (Ed.), Handbook of causal analysis for social research (pp. 301-328). Dordrecht, The Netherlands: Springer. https://doi.org/10.1007/978-94-007-6094-3

Cantril, H. (1965). The pattern of human concerns. New Brunswick, NJ: Rutgers University Press. 
Cheung, F., \& Lucas, R. E. (2015). Assessing the validity of single-item life satisfaction measures: Results from three large samples. Quality of Life Research, 23, 2809 - 2818. doi: 10.1007/s11136-014-0726-4.

Crawford, E. R., Lepine, J. A, \& Rich, B. L. (2010). Linking job demands and resources to employee engagement and burnout: A theoretical extension and meta-analytic test. Journal of Applied Psychology, 95,834 - 848. https://doi.org/10.1037/a0 019364

Demerouti, E. (2014). Design your own job through job crafting. European Psychologist, 19,237 - 243. https://doi.org/10.102 7/1 016-9040/a 000188

Devine, K., \& Hunter, K. H. (2017). PhD student emotional exhaustion: The role of supportive supervision and selfpresentation behaviors. Innovations in Education and Teaching International, 54, 335 - 344. https://doi.org/10.1080/14703297. 2016.1174143

Diener, E., Suh, E. M., Lucas, R. E., \& Smith, H. L. (1999). Subjective well-being: Three decades of progress. Psychological Bulletin, 125, 276 - 302. http://dx.doi.org/10.1037/0033-2909.125.2.276

Evans, T. M., Bira, L., Gastelum, J. B., Weiss, L. T., \& Vanderford, N. L. (2018). Evidence for a mental health crisis in graduate education. Nature Biotechnology, 36, 282 - 284.

Gallup. (2018). Understanding how Gallup uses the Cantril scale. Retrieved from https://news.gallup.com/poll/122453/understanding-gallup-uses-cantril-scale.aspx

Garcia-Williams, A. G., Moffitt, L., \& Kaslow, N. J. (2014). Mental health and suicidal behavior among graduate students. Academic Psychiatry, 38, 554 - 560. http://doi.org/10.1007/s40596-014-0041-y

Harju, L. K., Hakanen, J. J., \& Schaufeli, W. B. (2016). Can job crafting reduce job boredom and increase work engagement? A three-year cross-lagged panel study. Journal of Vocational Behavior, 95-96, 11 - 20. https://doi.org/10.1016/j.jvb.2016. 07.001

Ichheiser, G. (1943). Why psychologists tend to overlook certain "obvious" facts. Philosophy of Science, 10, $204-207$.

Juniper, B., Walsh, E., Richardson, A., \& Morley, B. (2012). A new approach to evaluating the well-being of PhD research students. Assessment and Evaluation in Higher Education, 37, 563 - 576. https://doi.org/10.1080/02 602938.2011 .555816

Kahneman, D., Alan, K., Schkade, D., Schwarz, N., \& Stone, A. (2006). Would you be happier if you were richer? A focusing illusion. Science, 5782, 1908 - 1910. https://doi.org/10.1126/science. 1129688

Kahneman, D., Krueger, A. B., Schkade, D. A., Schwarz, N., \& Stone, A. A. (2004). A survey method for characterizing daily life experience: The day reconstruction method. Science, 306, 1776 - 1780. https://doi.org/10. 1126/science. 1103572

Knight, C., Patterson, M., \& Dawson, J. (2017). Building work engagement: A systematic review and meta-analysis investigating the effectiveness of work engagement interventions. Journal of Organizational Behavior, 38, 792 - 812. https://doi.org/10.1002/job.2167

Kulikowski, K., \& Damziak, R. (2017). Współczesny uniwersytet oczami doktorantów - wymagania i zasoby studiów doktoranckich Raport z badania opinii doktorantów Uniwersytetu Jagiellońskiego [Contemporary University PhD programs in the eyes of doctoral students - demands and resources in the context of doctoral study programs. Research report on the opinion-based survey of doctoral students at the Jagiellonian University]. Nauka, 2, 85 - 105.

Levecque, K., Anseel, F., De Beuckelaer, A., Van der Heyden, J., \& Gisle, L. (2017). Work organization and mental health problems in PhD students. Research Policy, 46, 868 - 879. https://doi.org/http://dx.doi.org/1.1016/j.respol.2017.02.008

Payne, D. (2017, October 27). How to mentor your supervisor [Blog post]. Retrieved from http://blogs.nature.com/naturejobs/2017/10/27/how-to-mentor-your-supervisor/

Pearl, J. (2010). The foundations of causal inference. Sociological Methodology, 40, 75 - 149.

Pearl, J., \& Mackenzeie D. (2018). The Book of Why: The New Science of Cause and Effect. New York: Basic Books

Petrou, P., Demerouti, E., Peeters, M. C., Schaufeli, W. B., \& Hetland, J. (2012). Crafting a job on a daily basis: Contextual correlates and the link to work engagement. Journal of Organizational Behavior, 33, 1120 - 1141. http://dx.doi.org/10. 1002/job.1783

Sakuraya, A., Shimazu, A., Imamura, K., Namba, K., \& Kawakami, N. (2016). Effects of a job crafting intervention program on work engagement among Japanese employees: a pretest-posttest study. BMC Psychology, 4, 1 9. https://doi.org/10.1186/ s40359-016-0157-9

Salanova, M., Schaufeli, W., Martinez, I., \& Breso, E. (2010). How obstacles and facilitators predict academic performance: the mediating role of study burnout and engagement. Anxiety, Stress, and Coping, 23, 53 - 70. https://doi.org/1.1080/ 10615800802609965

Salmela-Aro, K., \& Upadyaya, K. (2014). School burnout and engagement in the context of demands-resources model. British Journal of Educational Psychology, 84, 137 - 151. https://doi.org/1.1111/bjep.12018 
Schkade, D. A., \& Kahneman, D. (1998). Does living in California make people happy? A focusing illusion in judgments of life satisfaction. Psychological Science, 9, 340 - 346. https://doi.org/10.1111/1467-9280.00066

Stubb, J., Pyhältö, K., \& Lonka, K. (2011). Balancing between inspiration and exhaustion: PhD students' experienced socio-psychological well-being. Studies in Continuing Education, 33, 33 - 35. https://doi.org/1.1080/0158037 X.201.515572

Taylor, L. A. (2018, November 6). Twenty things I wish I'd known when I started my PhD [Post]. Retrieved from https://www.nature.com/articles/d41586-018-07332-x

Tims, M., Bakker, A. B., \& Derks, D. (2012). Development and validation of the job crafting scale. Journal of Vocational Behavior, 80, 173 - 186. https://doi.org/10.1016/j.jvb.2011.05.009

Tims, M., Bakker, A. B., \& Derks, D. (2013). The impact of job crafting on job demands, job resources, and wellbeing. Journal of Occupational Health Psychology, 18, 230 - 240. http://dx.doi.org/10.1037/a0032141

Tims, M., Bakker, A. B., \& Derks, D. (2015). Job crafting and job performance: A longitudinal study. European Journal of Work and Organizational Psychology, 24, 914 - 928. https://doi.org/10.1080/1359432 X.2014.969245

Tsai, J. W., \& Muindi, F. (2016). Towards sustaining a culture of mental health and wellness for trainees in the biosciences. Nature Biotechnology, 34, 353 - 355. https://doi.org/10.1038/nbt.3490

Van Wingerden, J., Bakker, A. B., \& Derks, D. (2016). A test of a job demands-resources intervention. Journal of Managerial Psychology, 31, 686 - 701. https://doi.org/10.1108/JMP-03-2014-0086

Van Wingerden, J., Derks, D., \& Bakker, A. B. (2018). Facilitating interns' performance: The role of job resources, basic need satisfaction and work engagement. Career Development International, 23, 382 - 396. https://doi.org/10.1108/CD I-12-2017-0237

Wanous, J. P., \& Hudy, M. J. (2001). Single-item reliability: A replication and extension. Organizational Research Methods, 4, 361 - 375. doi: 10.1177/109442810144003

Wanous, J. P., Reichers, A. E., \& Hudy, M. J. (1997). Overall Job Satisfaction: How Good Are Single-Item Measures? Journal of Applied Psychology, 82, 247 - 252. https://doi.org/10.1037/0021-9010.82.2.247

Ward, A. M., \& Brennan, N. M. (2018). Developing a student doctoral education fit analytical model to assess performance. Studies in Higher Education. https://doi.org/10.1080/03075079.2018.1545758

Wrzesniewski, A., \& Dutton, J. E. (2001). Crafting a job: As active employees revisioning crafters of their work. Academy of Management Review, 26, 179 - 201. https://doi.org/10.2307/259118 